\title{
Simulation of Automatic Control of MFTF-B Neutral Beams
}

\author{
Edward Theil
}

\author{
Real Time Systems Group \\ Lawrence Berkeley Laboratory \\ University of Califormia \\ Berkeley, CA 94720
}

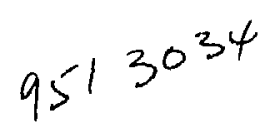

March 4, 1985

\section{DISCLAIMER}

\begin{abstract}
This report was prepared as an account of work sponsored by an agency of the United States Government. Neither the United States Government nor any agency thereof, nor any of their employees, makes any warranty, express or implied, or assumes any legal liability or responsibility for the accuracy, completeness, or usefulness of any information, apparatus, product, or process disclosed, or represents that its use would not infringe privately owned rights. Reference herein to any specific commercial product, process, or service by trade name, trademark, manufacturer, or otherwise does not necessarily constitute or imply its endorsement, recommendation, or favoring by the United States Government or any agency thereof. The views and opinions of authors expressed herein do not necessarily state or reflect those of the United States Government or any agency thereof.
\end{abstract}

This work was sponsored by TRW Corporation under TRW/DOE Agreement 85-27 through the U.S. Department of Energy under Contract No. DE-AC03-76SF00098 


\title{
Simulation of Automatic Control of MFTF-B Neutral Beams
}

\author{
Edward Theil \\ Real Time Sysiems Group \\ Lawrence Berkeley Laboratory \\ University of Califomia \\ Berkeley, California 94720
}

March 4, 1985

\section{Introduction}

This report ${ }^{1}$ describes the results obtained by using data generated at Lawrence Livermore Laboratory's MFS Test Facility as input to the filtering and control programs developed at LBL. Graphs that illustrate the source models/filters performance, as well as some conditioning history are included. Probable sources of error are discussed.

\section{Method}

Waveform averages were read by eye from console displays and entered by hand into computer files for each shot. These files were transferred electronically to LBL where they were edited to eliminate obvious typing and formatting errors. At the same time, some preliminary analysis took place to determine the dats's structure and to provide starting values for the Kalman filters used in estimation.

The files were then used as input data to the control program. This program is algorithmically identical to one used to control TFTR sources several years ago. ry.

'This work was ponsored by TRW' Corporation under TRW/DOE Agreement 85-27 with Lawrence Berleley Laborato- 
The RCA short pulse NBI's are fairly simple and well-behaved from a controls point of view. Typically, the operator chooses a value of $\boldsymbol{P}_{\text {arc }}$ (on the basis of expericnce) which Tesults in the desired $I_{\text {accel }}$ or something close to it. The resulting arc current and voltage zre determined by power supply characteristics and are not contiolled directly.

Imagine that the operator has two knobs to control the two primary values: $V_{\text {arcel }}$ and perveance. Using $I=p v^{1.5}, I_{\text {acrel }}$ is determined from the two knob values. (Alternatively, one can set perveance by a tuning mechanism and eliminate the second $k n o b)$.

The simulation assumes that the two knobs have been been set with the measured $V_{\text {arel }}$ and perveance. The computer's job is to replace the operator's guess of $\boldsymbol{P}_{\text {arc }}$ However, the control program was asked to predict $I_{\mathrm{arc}}$ and $V_{\mathrm{arc}}$ as well, both as a matter of interest (see Results, below) and because these may prove necessary for control of long pulse beams. Filament settings were ignored, since they generally do not change during the course of a run, and were not recorded in any case. (This would not be true for emission-limited operation). Figure 1 is a generalized block diagram of the system.

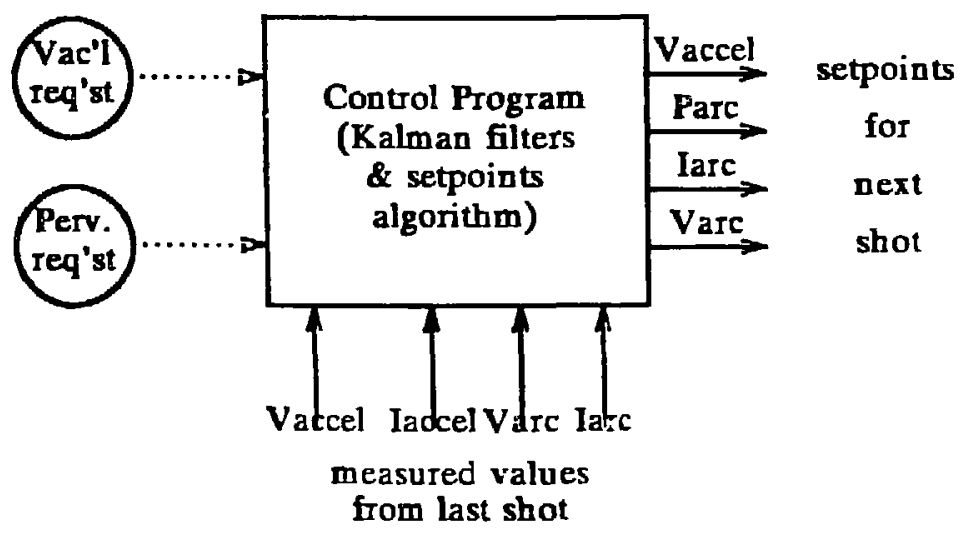

Figure 1 


\section{Results}

Therc are several categories of output rellected in the attached graphs:

\subsection{Siate Varlables}

The Kalman filters produce estimates of the "state" of the source, from which the power supply requirements are indirectly derived. For example, one element of the state is the orc impedance, $\alpha$, from the model

$$
V_{\mathrm{urc}}=\mathbf{\alpha} I_{\mathbf{a r}}+\boldsymbol{\beta} \text {. }
$$

Another quantity of interest is the arc efficiency: a measure of how much beam current is obtained for each additional kilowatt of arc power. That value is $p$ in the expression

$$
I_{\text {acrel }}=\rho P_{a x}+\delta \text {. }
$$

Needless to say, these quantities vary over time. Nevertheless, the first two graphs indi cate that they were reasonably steady during the conditioning of source T4. One might guess, for example, that the gas flow was varied very little during the run, since that should have an obvious effect on $\alpha$.

Recent MFSTF experience indicates difficulty in reaching the goals of $80 \mathrm{Kv}$ and 80 amps consistently, raising the possibility that the arc power required to produce 80 amps of ions may be stretching the source's capability. To avoid this problem, one might either run at less than $80 \mathrm{Kv}$ or run at $80 \mathrm{Kv}$ with less than 80 amps. But a possible altenative suggests itself in the light of these two state variables: one might initiate an experimental program to determine if the arc efficiency can be increased by varying operational parameters (e.g., gas flow and/or filament temperature). Experience at NBETF has shown that both of these parameters do indeed affect the efficiency. (These observations are made primarily to illustrate the kind of information available from the models). 


\subsection{Predicting the Power Supply Values}

The next set of six graphs show the relative error in the models' predictions. Given $I_{\text {accel }}$, the computed predictions are compared with the actual measured values for each shot: (measured - predicted)/measured, expressed as a percentage. The errors were also histogrammed. Points to note here are that the worst errors (5 to 6\%) occur less than $1 \%$ of the time and $95 \%$ of the almost 700 shots recorded had errors of less than $3 \%$. A discussion of the sources of error appears below.

\subsection{Conditioning History}

The final set of five graphs show a history of the conditioning of beam T4. They include a history of $v_{\text {acrel }}$, ontime/req.time and ontime/number of tries. These graphs are included as a matter of interest and are not directly related to the main subject of single shot automatic control. They do, however, illustrate the usefulness of an easily accessible archive of shot data.

Note hox noisy both signals are, although ontime/interrupt has discern:ble trends. Consequently, I produced filtered versions of both. It would appear that time/try is a better index of conditioning than on/req., on the basis of the present data.

\section{Discussion}

The most important results are expressed in the relative error graphs. They strongly suggest that the computer can be used to predict required power supply values with high accuracy for the 0.5 second RCA NBI's. 
Even so, 1 belicve that performance in practice might actually be better than that shown in the simulation. There are two reasons for this belief:

(1) A princifal source of error is the roundofi due to "eyeballing" the waveforms. For example, $J_{\text {arr }}$ appears to be rounded to the nearest 25 amps and $V_{\text {arc }}$ to the nearesi 0.5 volts most of the time. Using half of those values as average errors introduced by rounding results in around $1 \%$ for both $I_{\mathrm{arc}}$ and $V_{\text {arr }}$ and somewhat greater error for $P_{\text {arc }}$ Since the average error in the predictions was less than $2 \%$, a significant improvement might be expected simply by introducing accurate waveform averaging. What would probably result would be very slightly larger average error, but with a smaller variance. That is, we would ixpect that the largest deviations from measured would decrease.

(2) The other (much smaller) source of error is that time did not permit me to "tune" the filters very well. Consequently, they tended to respond too quickly to aberrant data, causing some wider oscillations than would normally occur during actual operation. It is bard to see these among the 700 odd shots recorded, but they are there.

Incidentally, although $P_{\text {arc }}$ was recorded by the operator, almost never did it match the product of $I_{a r c}$ and $V_{\text {anc }}$, the former being consistently lower than the product. If an signal analogue to $P_{\text {arc }}$ was monitored, it might have a gain or offet problem. Consequently, the recorded value of $P_{\text {arc }}$ was ignored and $I x V$ was used instead.

\section{Conclusions}

The graphs show that this approach to beam control can be used with confidence for the RCA injectors. This is particularly important during multi-beam operation where the 
number of parameters per beam must be kept io a minimum.

No change in the control algorithm was necessary in order to run our programs on the MFSTF data. The only changes required are in data input parameters that reside in files read by the programs. In other words, the control program can be treated as a black box, once its input parameters are adjusted. This is particularly important for MFTF operation where there will be two distiuct types of beams, as well as small variations among NBI's even of the same type. It means that the number of different programs for different beams can be minimized and should be very small (one or two).

Finally, it is important also to point out what has not been done in this study. We deal here with shor-ro-shot automatic control. The problem of automatic conditioning (automatic control over a series of shots) is only incidentally addressed, although LBL has developed algorithms in this area as well. The two topics are probably of equal importance. In the first place, it is hard to see how to implement automatic conditioning without first having automatic shot control. Second, $V_{\text {acrel }}$ in MFTF operations will be determined primarily by physics requirements, not by conditioning. Of course, some conditioning will go on anyway, between injections, so any computer assistance in that regard would be desirable on the Mirror Machine, as well as on the test stand.

\section{Acknowledgment}

It is a pleasure to thank Dr. Bob Huff of TRW for proposing and facilitating this study. 
ARC EFFICIENCY

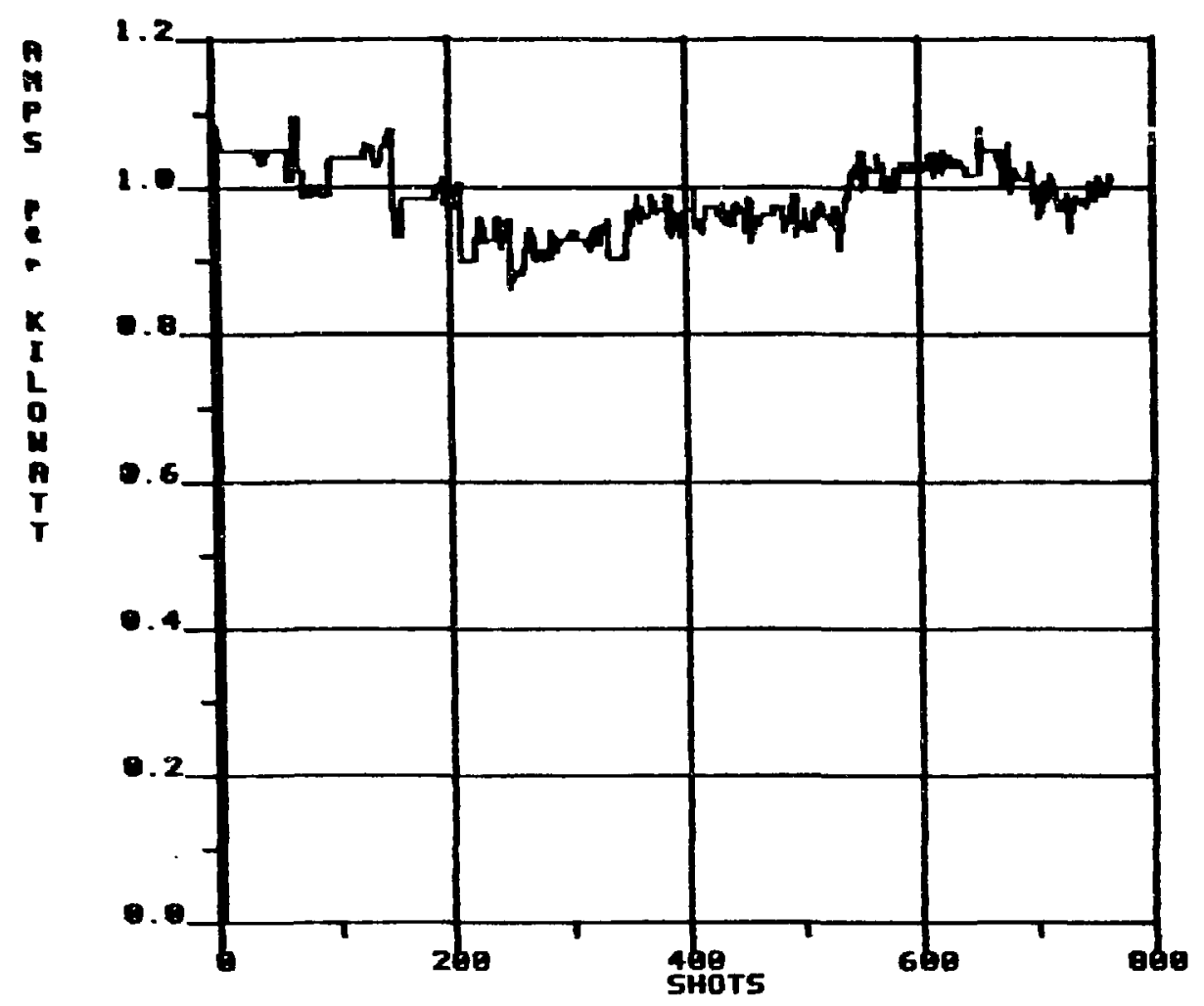

ARC IMPEDRNCE

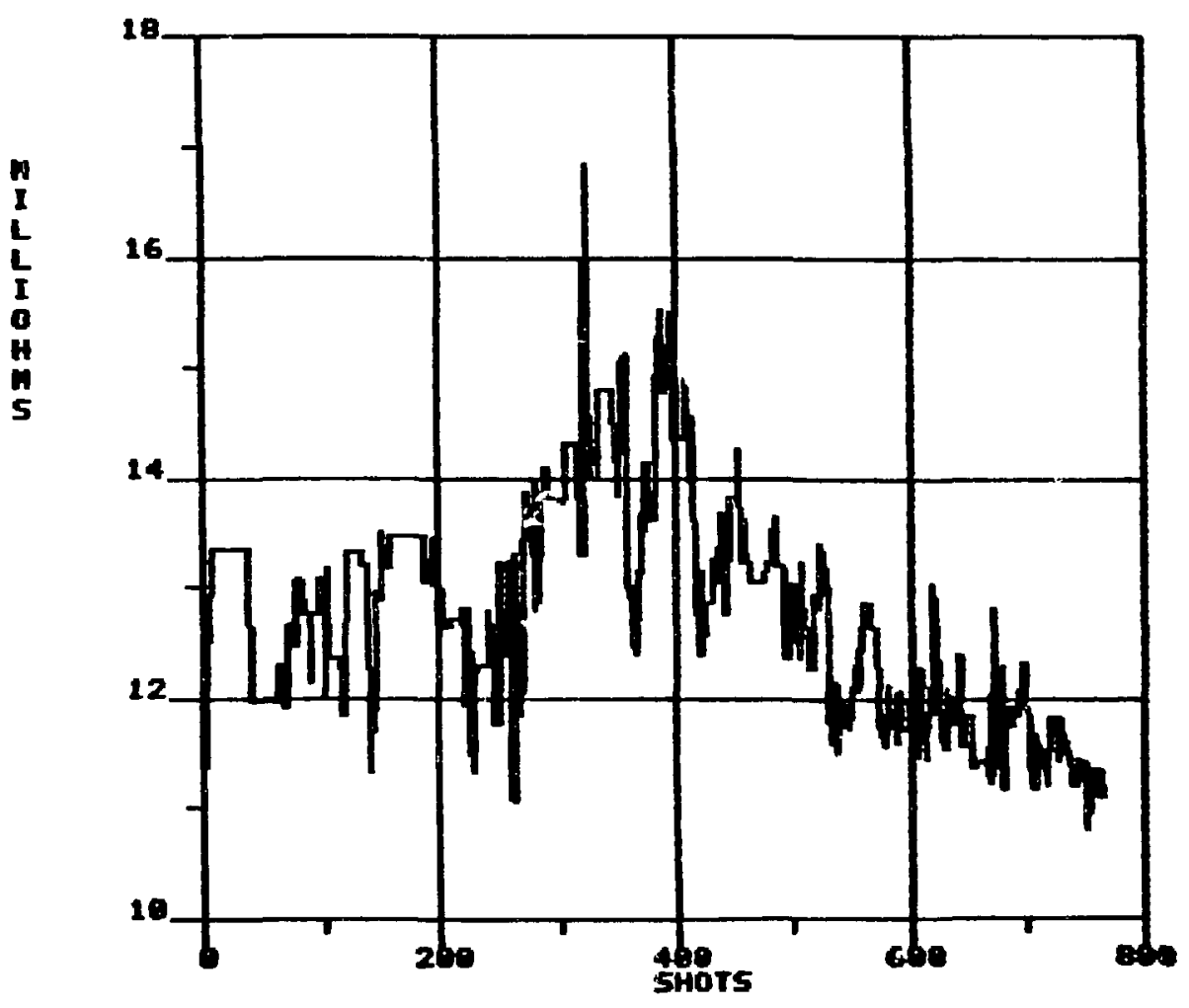



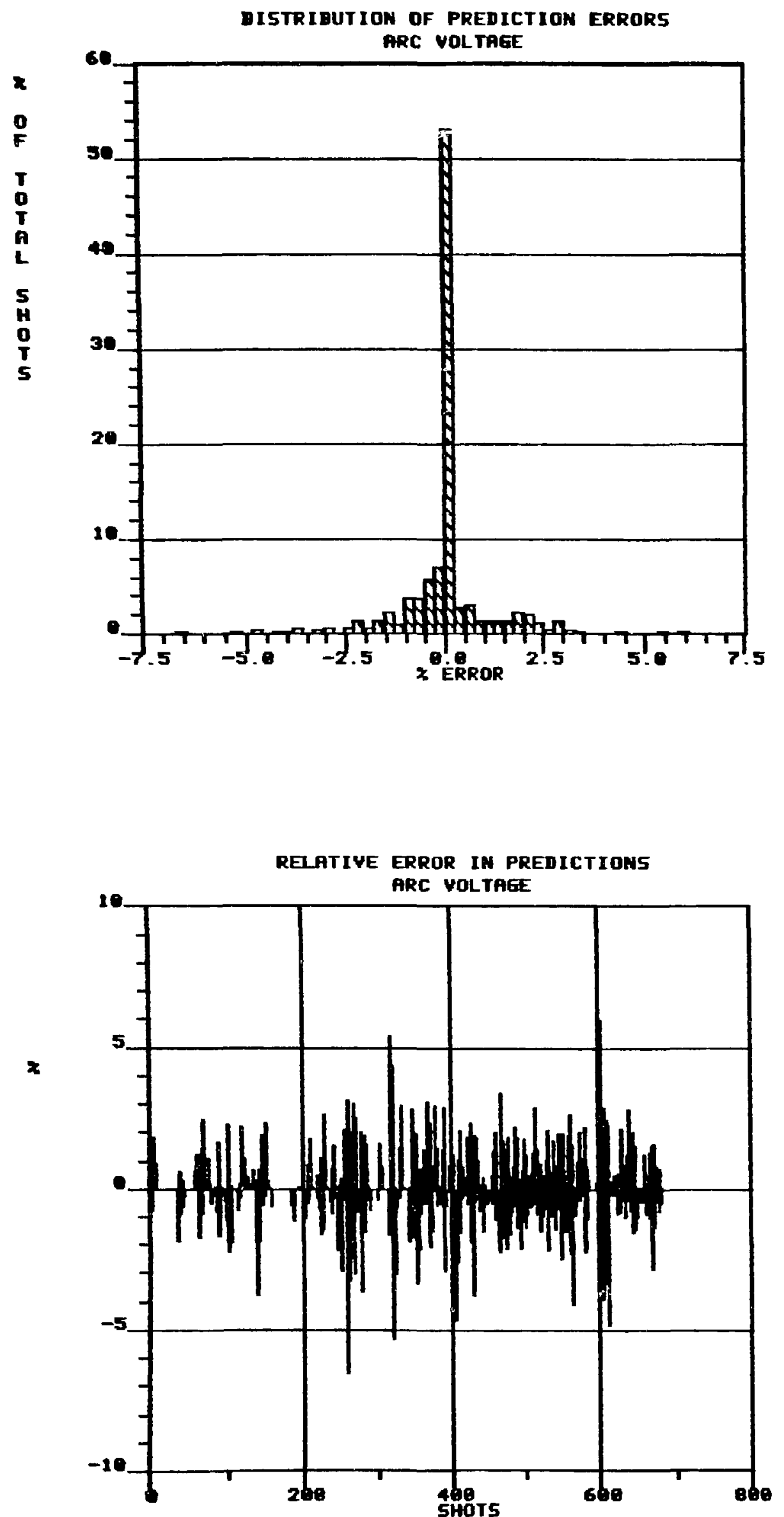

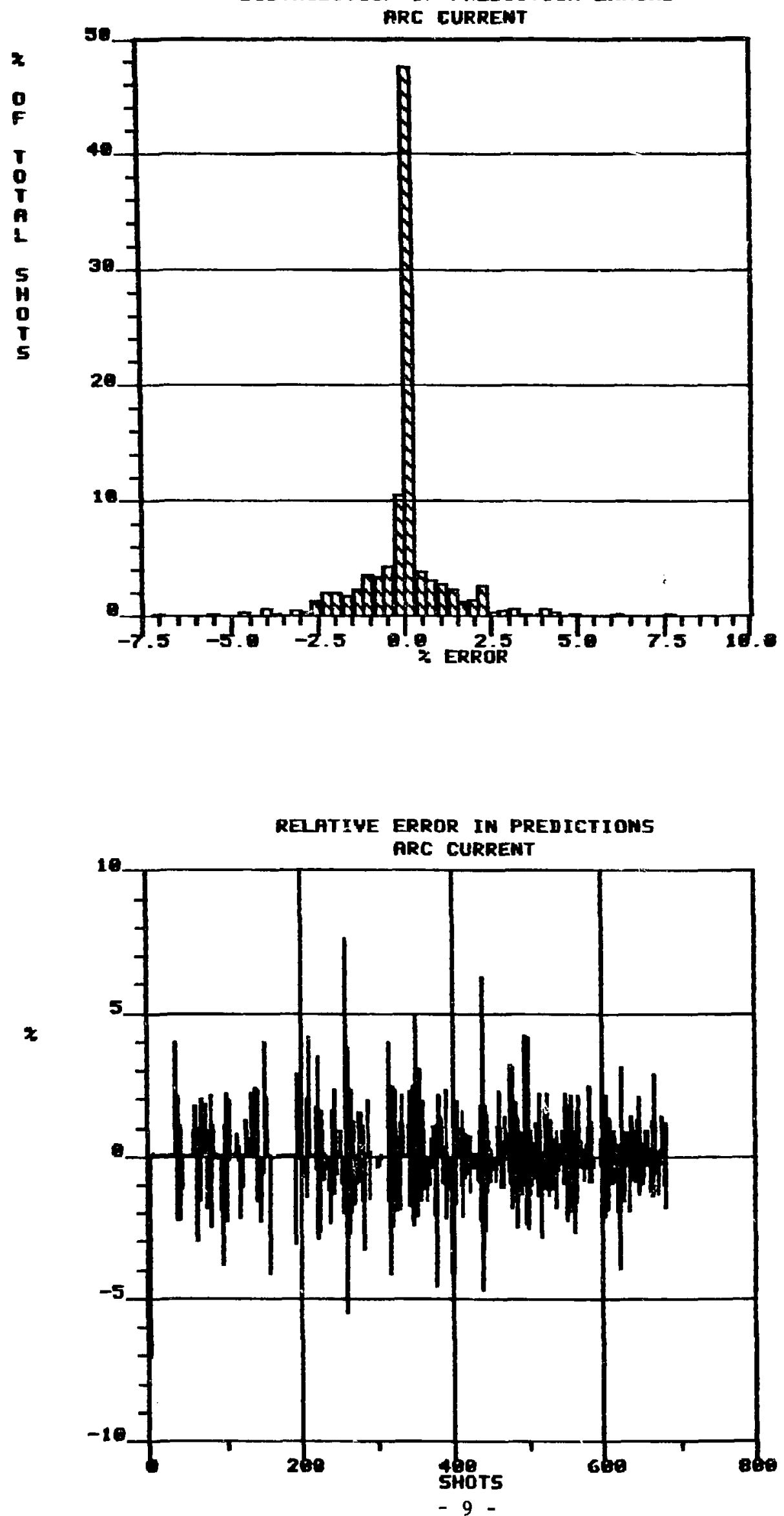

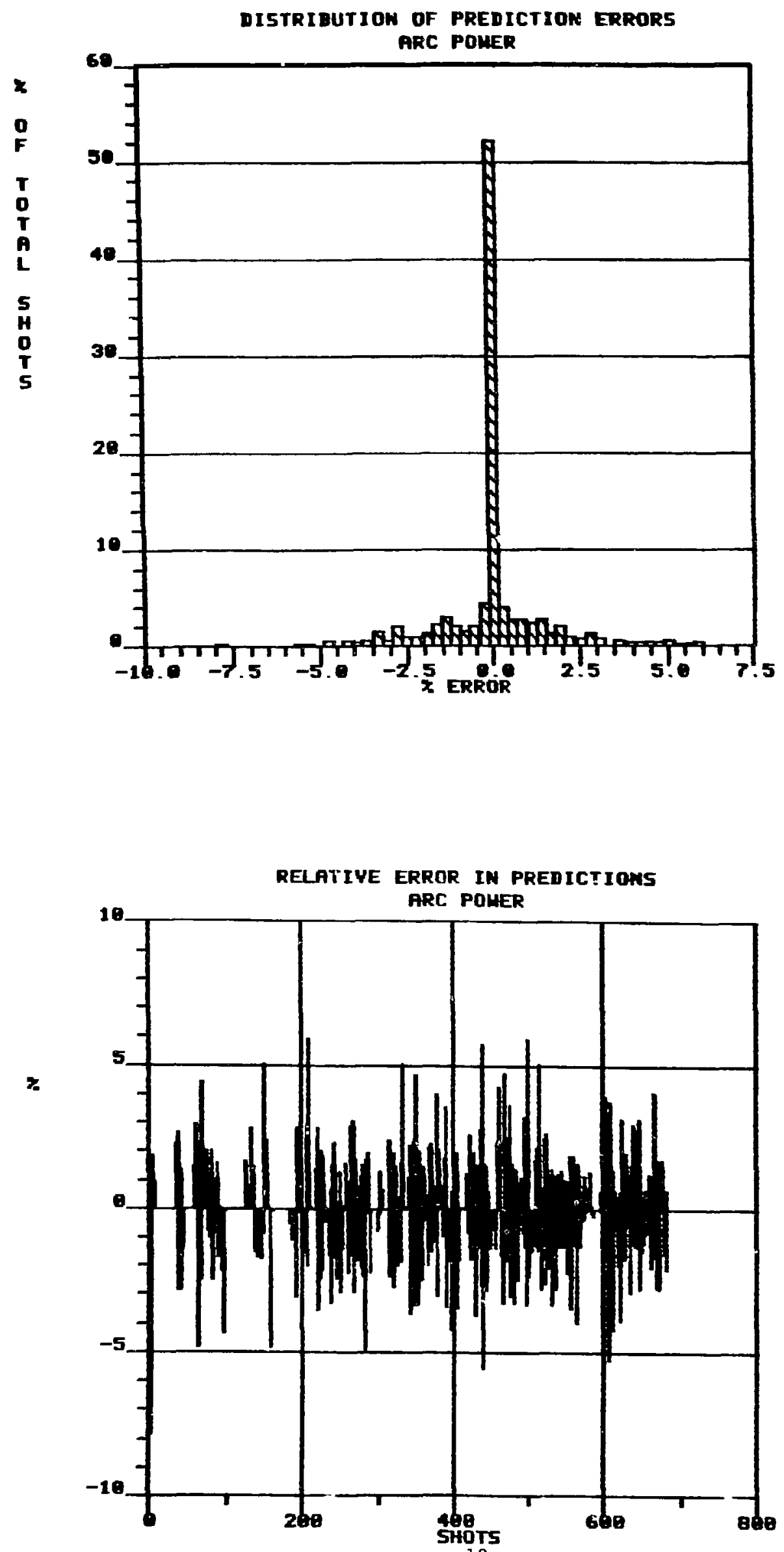


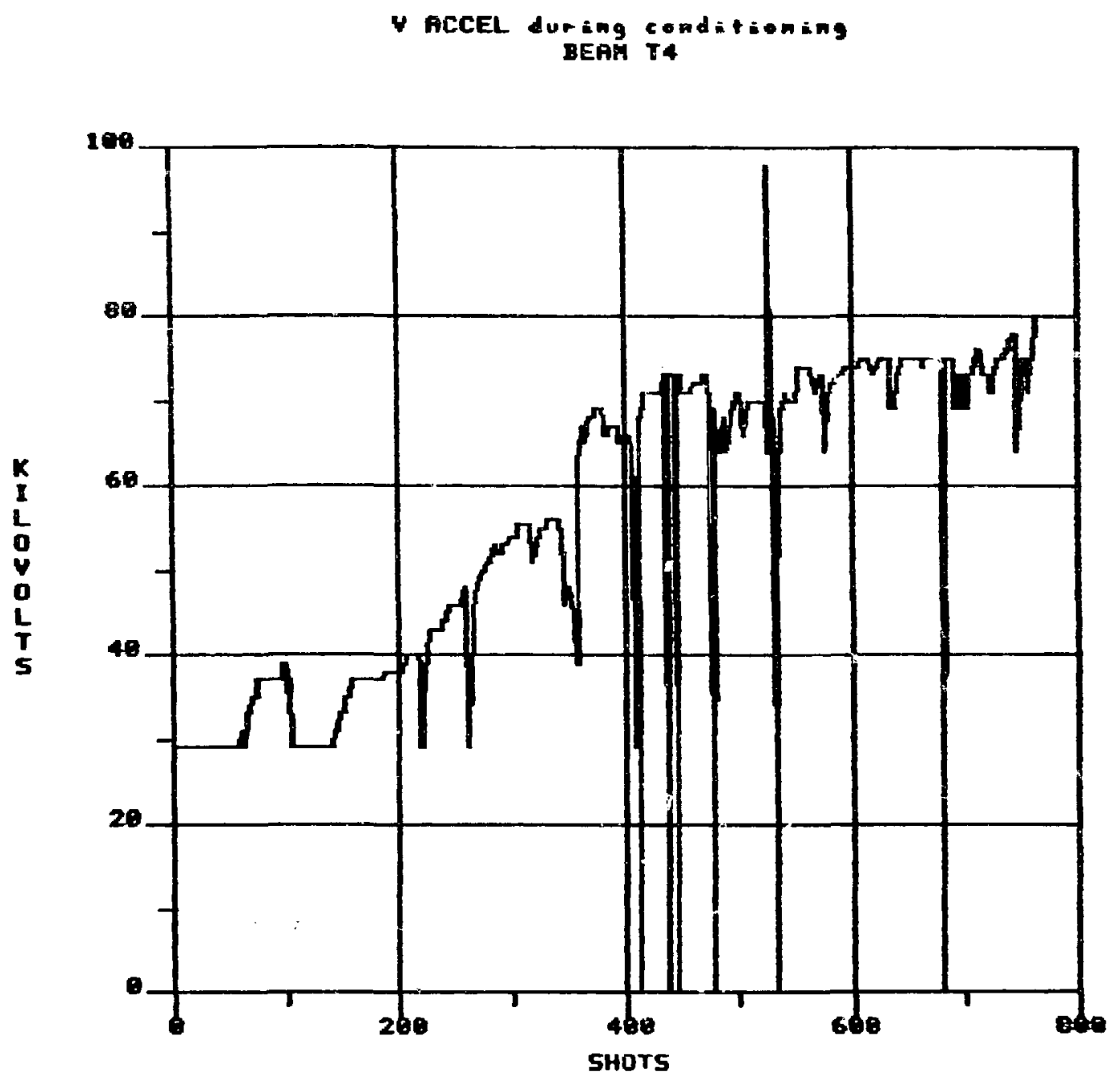


DEAN TA CONDITIONING hISTORY ONTIMEPREO . TIME

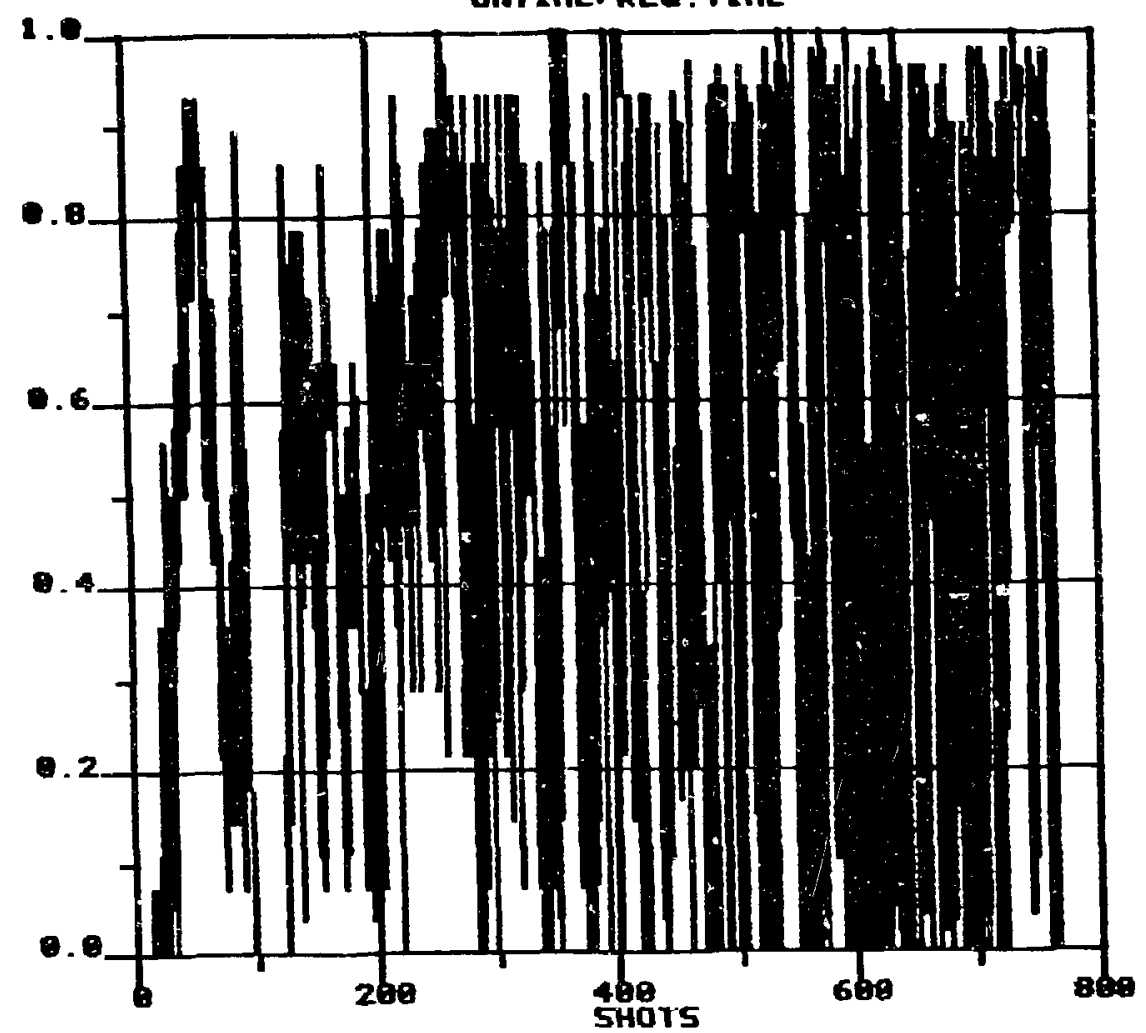

BEAH T4 CONDITIONIMG HISTORY

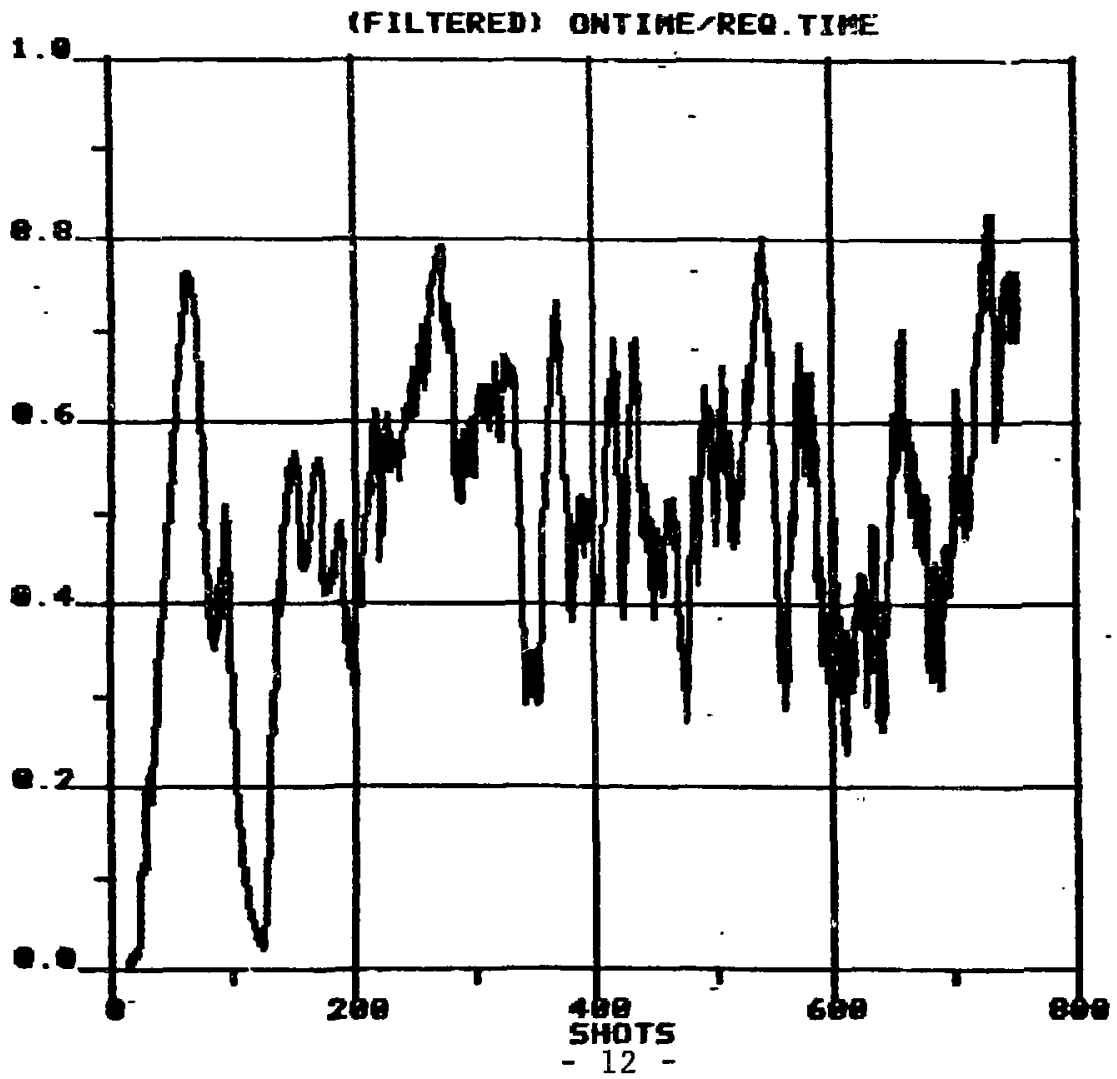



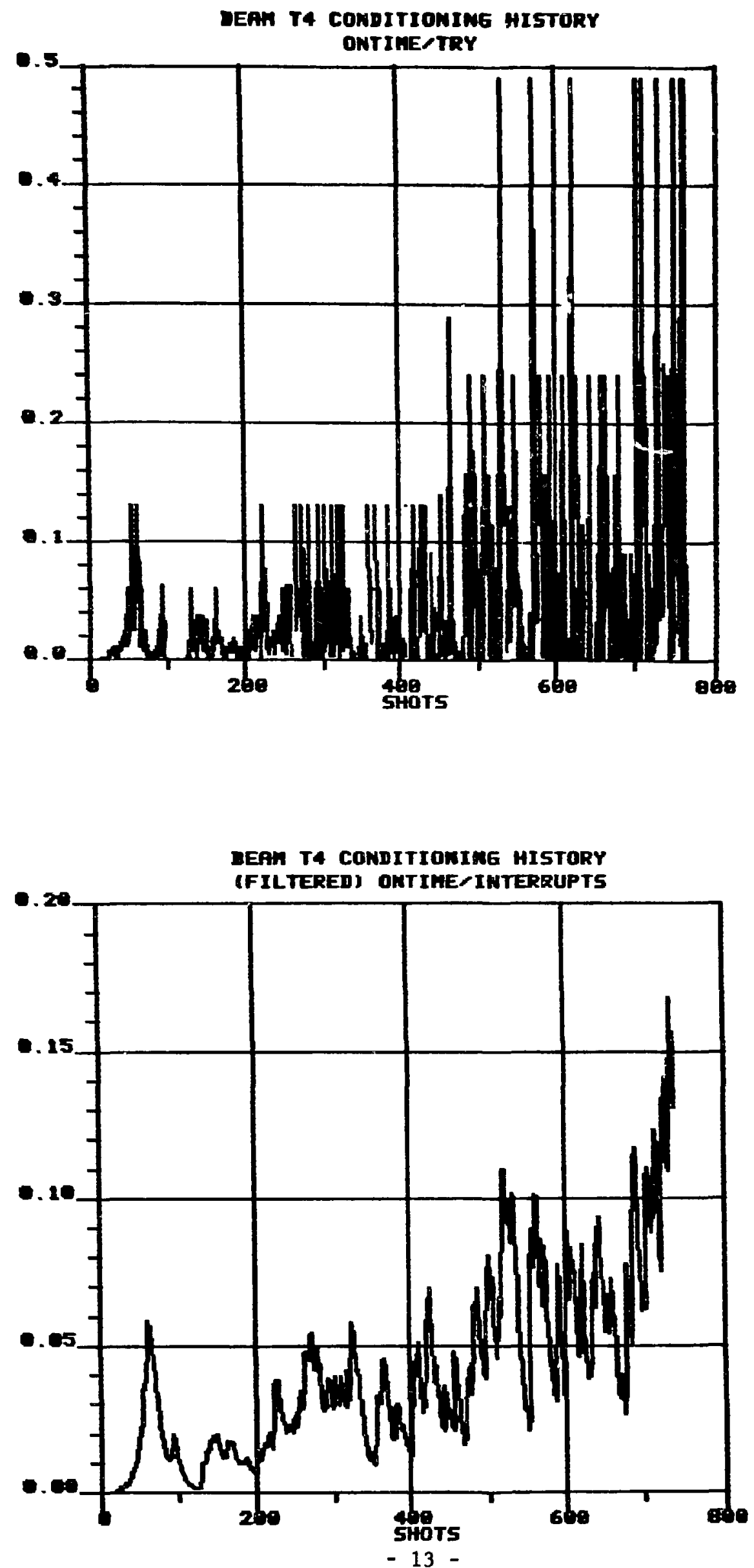